\title{
Uma análise sobre o desenvolvimento da Política Nacional de implementação da Justiça Restaurativa no estado de São Paulo
}

\section{An analysis of the development of the National Policy for implementing Restorative Justice in the state of São Paulo}

Débora Eisele Barberis ${ }^{1}$

\begin{abstract}
Resumo: O presente artigo pretende realizar uma análise dos aspectos estruturais e práticos do processo de implementação da Política Nacional de Justiça Restaurativa no âmbito do Judiciário a partir da Resolução do Conselho Nacional de Justiça $n^{\circ} 225$, representante do marco normativo. Procurando entender 0 motivo das dificuldades enfrentadas pela implantação das práticas restaurativas no estado de São Paulo, mais especificamente na capital, bem como os mecanismos utilizados para contornar tais obstáculos. Além dos aspectos formais próprios para o desenvolvimento de uma política pública, pretende-se também atentar para os propósitos da Justiça Restaurativa em contraponto com a institucionalização de suas práticas.
\end{abstract}

Palavras-chave: Justiça Restaurativa, implementação, política pública, institucionalização.

\begin{abstract}
The present article intends to carry out an analysis of the structural and practical aspects of the process of implementation of the National Policy of Restorative Justice in the scope of the Judiciary, based on Resolution of the National Council of Justice $n^{\circ} 225$, representative of the normative framework. Trying to understand the reason for the difficulties faced by the implantation of the restorative practices in the state of São Paulo, more specifically in the capital, as well as the mechanisms used to overcome such obstacles. In addition to the formal aspects proper to the development of a public policy, it is also intended to attend to the purposes of Restorative Justice in counterpoint to the institutionalization of its practices.
\end{abstract}

Keywords: Restorative Justice, implementation, public policy, institutionalization.

\section{Introdução}

A Justiça Restaurativa e suas práticas estão ganhando destaque cada vez maior devido à crise institucional vivida pelo poder judiciário e sua busca por implementar práticas alternativas de resolução de conflitos como a mediação e a conciliação e mais recentemente as práticas restaurativas.

\footnotetext{
${ }^{1}$ Mestre em Direito Político e Econômico pela Universidade Presbiteriana Mackenzie com tema da Justiça Restaurativa. Advogada, Mediadora, Facilitadora e Formadora de facilitadores de Processos Circulares. Professora do Curso de Formação de Facilitadores promovido pelo TJ (SP). Facilitadora no curso de Fundamentos da Justiça Restaurativa do CDHEP. Email:deboraebarberis@hotmail.com
} 
De maneira crescente vão sendo desenvolvidos métodos de implementação dessas práticas alternativas de administração de conflitos dentro do judiciário como tentativa de conter a crise de alta demanda de processos e a falta de legitimidade e satisfação com as respostas e soluções dadas aos problemas levados à essa instituição.

Sendo assim, para que possa ser realizada uma análise do processo de implementação das práticas restaurativas e da política de maneira geral pretende-se primeiramente abordar a definição que será adotada no presente trabalho e na qual serão pautadas as considerações acerca das suas dimensões e seus propósitos.

Outro momento será de contextualização da implementação da Justiça Restaurativa no Brasil até o surgimento do ato normativo principal responsável pela criação da Política Nacional para posteriormente abordar a situação e a estrutura encontrada no processo desenvolvido especificamente no estado de São Paulo.

Já em um terceiro momento a proposta é tratar dos aspectos principais relacionados à uma política pública em geral, para partir de uma estruturação necessária para que possibilite, após a contextualização da Justiça Restaurativa como política nacional, abordar as dificuldades de articulação e de organização.

Por último se propõe a entender, para além dos aspectos estruturais, os propósitos da Justiça Restaurativa e de que maneira acabam por dificultar o processo de institucionalização de suas práticas.

Considerando a recente estipulação da Política Nacional, a necessidade de se pensar outras formas de tratar os conflitos e a complexidade das práticas restaurativas, exige-se cautela em todo os processos de implementações.

\section{Justiça Restaurativa}

A Justiça Restaurativa, ainda que já tenha um percurso em torno de 40 anos de desenvolvimento no contexto internacional em países como Canadá, Estados Unidos e Nova Zelândia, e no Brasil desde 2005, não possui uma definição única ${ }^{2}$. A maior convergência de opiniões é a respeito dos princípios norteadores das suas práticas.

\footnotetext{
${ }^{2}$ A falta de definição única e final do que seja a Justiça Restaurativa deve-se ao cuidado da possibilidade de limitação de seu alcance e potencial quando inserida em uma categoria fechada, ainda que manter dessa forma mais aberta cause a falta de concretude do que se trata.
} 
Ainda que haja essa multiplicidade de definições opta-se por adotar uma em específico que mais se alinha com os pensamentos a serem desenvolvidos e para que possam as reflexões partirem de algo mais concreto.

A definição é a elaborada por João Salm ${ }^{3}$ (2017) que propõe a Justiça Restaurativa como um conjunto de princípios e práticas que por meio da participação direta, deliberação, diálogo, em um processo de educação e de conhecimento sobre o outro, sobre a justiça do outro, e é assim que adquirimos conhecimento sobre nós mesmos. Essa justiça não está localizada em uma instituição, ela está na curiosidade de cada individuo sobre algo, alguém, de forma coletiva.

Pautada por essa definição podemos observar, já de início, a grande diferença de apenas definir a Justiça Restaurativa de forma superficial como uma forma alternativa de resolução de conflitos, se resumindo a uma prática a ser utilizada pontualmente em casos específicos e por outro lado, aprofundando seu conceito, se referir a Justiça Restaurativa como uma nova forma de se relacionar e de se pensar a justiça.

Um outro aspecto importante é a mudança de olhar para o significado da justiça. Enquanto no judiciário justiça tornou-se sinônimo de decisão judicial e, ainda assim, não refletindo esse sentimento do justo para as pessoas que passam pelo processo, na Justiça Restaurativa a justiça é encarada como um valor compartilhado pela comunidade e que é construído, assim como afirma Salm (2017), de forma coletiva no processo relacional.

Importante também destacar os princípios norteadores que, segundo o autor, pautam as práticas restaurativas, sendo considerados como estruturantes da Justiça Restaurativa. O primeiro principio é o que ele chama de valores humanizantes que são os valores que usamos como referência para interagirmos uns com os outros como respeito, amor, empatia.

O segundo princípio trata sobre as relações, considerando que o indivíduo é ele mais suas relações, tanto com os outros quanto com o meio ambiente, com a perspectiva

\footnotetext{
${ }^{3}$ João Salm é professor do Departamento de Justiça Criminal da Governors State University, em Chicago (EUA), codiretor do Centro de Justiça Restaurativa do Skidmore College, em Nova York e membro do comitê de direção do Centro de Justiça Restaurativa na Universidade Simon Fraser, em Vancouver, Canadá, bem como um dos coordenadores da cooperação internacional entre o Canadá, Estados Unidos e Brasil na área da Justiça Restaurativa.
} 
de que quando causo dano em alguém eu causo nessa pessoa e em suas relações, a ideia de dano compartilhado (trazendo a ideia que a Justiça Restaurativa é um pensar relacional).

O terceiro princípio é sobre a responsabilidade que para além de considerar a individual da pessoa que causa o dano, torna como central a responsabilidade coletiva que não se refere somente ao que aconteceu, mas também sobre o plano de ação do que vai acontecer. Aqui entende-se que quando um individuo causa um dano, tem uma atitude prejudicial com uma relação, aquela comunidade a qual ele pertence também é responsável pela situação, justamente porque não podemos entender o individuo sozinho, descolado de seu contexto social e de suas relações.

O quarto princípio é referente a tratar o dano, abrindo possibilidades para explorar mais as injustiças sociais, ecológicas e distributivas. O tratar o dano vai muito além e é muito mais complexo que dar uma resposta punitiva a indivíduos específicos, o que se pretende com essa lógica é poder explorar os conflitos para além de uma conduta que afetou relações, mas poder, na sua essência, transformar relações, tanto entre indivíduos como entre esses indivíduos e sua comunidade e meio ambiente.

Desse modo cria-se a possibilidade de repensar estruturas desiguais e opressoras a partir de conflitos que em um primeiro momento podem aparentar apenas uma problemática individual de relacionamento mas que muito guardam relação com as estruturas que a sociedade está pautada e com a proposta de entender o conflito apenas como um ponto de partida e não como ponto de chegada proporciona a abertura para ressignificar padrões de comportamento e de reprodução de desigualdades, inclusive, questionando em um pais como o Brasil, as violências perpetradas pelo próprio Estado.

O quinto e último aborda o fortalecimento da comunidade, considerando o ser humano como um ser multidimensional e que deve ser considerado em seu contexto e fortalecido com suas relações em sua comunidade. O conceito de comunidade aqui empregado se trata de um conceito multi-dimensional que inclui aspectos afetivos, políticos, criativos e coletivos. São as micro-sociedades em que sentimos algum nível de envolvimento fora de nossos lares (ELLIOT, 2011, pg. 196). Como afirma João Salm 
e, portanto, a sua coprodução a partir da mútua aprendizagem, como também a coresponsabilidade pelos rompimentos e pelas suas soluções. Frisa-se neste ponto a importância do potencial construtivo e transformativo que surge da participação social a partir da multidimensionalidade humana calcada no diálogo; ainda, que permite um processo crescente de sentimento de pertença e que redunda em diminuição dos estranhamentos, ou, pelo menos, em formas diferentes e alternativas de trabalhar com esses estranhamentos e essas diferenças. (SALM, LEAL, 2012, p. 207).

Ainda sobre o aspecto de fortalecimento da comunidade, a ideia é de reconhecer a autonomia da comunidade de lidar com os seus conflitos diários, assim como George Pavilch (1996) afirma que os conflitos nascem na comunidade então nada mais coerente que fazer um movimento de devolver para a comunidade a possibilidade de se engajarem na resolução deles.

Após a breve passagem pela definição aqui adotada sobre Justiça Restaurativa, e antes de adentrar ao movimento de implementação de suas práticas no Brasil, importante destacar que as práticas mais conhecidas e que foram e são utilizadas no país são chamadas de círculo vítima-ofensor, círculo de construção de paz e conferência familiar.

De forma breve, sem a pretensão de esgotar as explicações, cabe aqui apenas diferenciar de forma geral as práticas, podendo-se dizer que o círculo vítima-ofensor é o mais utilizado na área criminal por partir de um conflito específico para construção de um consenso, sendo a conferência familiar muito parecida, mas tratando especificamente de conflitos e relações familiares. Já os círculos de construção de paz abordam conflitos de qualquer forma, considerando que são inerentes às relações humanas, mas ao mesmo tempo, não foca a partir de um fato pontual buscando muito mais o fortalecimento das relações.

Todas as práticas que envolvem a Justiça Restaurativa ainda que apresentem dinâmicas diferentes todas devem estar pautadas nos princípios norteadores há pouco elencados, de modo que independente da metodologia o núcleo de valores e princípios norteiem as práticas realizadas com os propósitos restaurativos.

\section{Início do processo de implementação da Justiça Restaurativa no Brasil}

O processo de implementação das práticas restaurativas no Brasil, teve início no ano de 2005 a partir do projeto "Promovendo Práticas Restaurativas no Sistema de Jus- 
tiça Brasileiro" que contou com a parceria entre a Secretaria da Reforma do Judiciário do Ministério da Justiça e o Programa das Nações Unidas para o Desenvolvimento (PNUD) que implementou 3 projetos-piloto pelo país, sendo um em Brasília (DF), outro em São Caetano do Sul (SP) e um em Porto Alegre (RS).

Cada um dos projetos-piloto estava alocado em um âmbito específico, porém todos, de alguma forma, conectados ao contexto macro do judiciário. O objetivo dos três projetos, de maneira geral, era avaliar o impacto da aplicação dos princípios da justiça restaurativa na abordagem das relações entre infrator, vítima e comunidade, além de fundamentar as práticas junto ao Sistema de Justiça Juvenil (ARRUDA; JOÃO, 2014, p. 202-203).

O projeto-piloto de Brasília foi realizado nos 1ํ e 2ํㅡㄴ Juizados Especiais de Competência Geral do Núcleo Bandeirantes atuando nos casos de competência do Juizado Especial Criminal com as infrações de menor potencial ofensivo. A prática restaurativa utilizada foi a mediação vítima-ofensor e eram utilizados em casos nos quais as relações tinham projeções para o futuro. Esses casos eram selecionados por juízes, promotores e equipe técnica, não sendo escolhidos casos de violência doméstica e de uso de substâncias entorpecentes (RAUPP, BENEDETTI, 2017).

Já o realizado em São Caetano do Sul foi concretizado na Vara da Infância e Juventude e dentro de escolas. A Vara, em conjunto com a Promotoria, ficou responsável pela seleção dos casos bem como a verificação dos termos de acordo, abrangendo seu cumprimento. No caso de o acordo ter sido cumprido era feito o requerimento ao juiz para que concedesse remissão ao caso. No ano de 2006, o projeto foi ampliado para outras escolas estaduais no bairro de Heliópolis, em São Paulo, e na cidade de Guarulhos, com o apoio da Secretaria de Estado da Educação de São Paulo e das respectivas Varas da Infância e da Juventude.

Por fim, o desenvolvido em Porto Alegre levou o nome de "Justiça para o Século

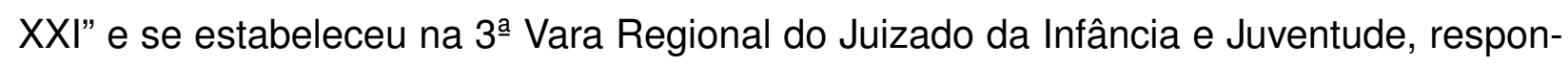
sável pela execução de medidas socioeducativas. Os círculos eram realizados em duas frentes, uma antes de ocorrer a representação e outra durante a execução da medida socioeducativa, além de ter se tornado um polo de formação e capacitação de servidores 
públicos.

Concomitantemente, no ano de 2006, foi apresentado o projeto de lei PL 7006/2006 que foi elaborado com a finalidade de facultar o uso de procedimentos de Justiça Restaurativa no sistema de justiça criminal, em casos de crimes e contravenções penais, pretendendo modificar o Código de Processo Penal, porém por conter problemas em sua redação, como mais a frente será trabalhado, o projeto legislativo está ainda em desenvolvimento.

De maneira geral esses foram os três projetos-piloto que se transformaram em um marco para a implementação da Justiça Restaurativa no Brasil, sendo que todos se iniciaram no período anterior a existência de um marco normativo.

\section{Aspectos principais e estruturais de uma política pública}

Importante contextualizar os aspectos principais sobre o que se trata política pública para que posteriormente seja possível analisar a estruturação e o processo de implementação das práticas restaurativas no estado de São Paulo, mais especificamente na capital. Assim sendo, para que a análise parta de um referencial teórico.

Política pública é o programa de ação governamental que resulta de um
processo ou conjunto de processos juridicamente regulados - processo
eleitoral, processo de planejamento, processo administrativo, processo
judicial - visando coordenar os meios à disposição do Estado e as ati-
vidades privadas, para a realização de objetivos socialmente relevantes
e politicamente determinados. Como tipo ideal, a política pública deve
visar a realização de objetivos definidos, expressando a seleção de prio-
ridades, a reserva de meios necessários à sua consecução e o intervalo
de tempo em que se espera o atingimento dos resultados. (BUCCI, 2006,
p.39)

A partir da conceituação desenvolvida por Maria Paula Dallari Bucci e como bem colocado por Clarice Seixas Duarte (2013), a política pública possui 4 elementos principais estruturantes, quais sejam: ação, coordenação, processo e programa.

A ação se refere ao fato de que as políticas públicas têm por objetivo a efetivação dos direitos sociais que têm como estrutura um conjunto de prestações positivas, as fáticas e as jurídicas. As primeiras se relacionam aos bens concretos pelo Estado fornecidos, como por exemplo os serviços públicos de saúde, já as prestações jurídicas dizem respeito as proposições normativas necessárias para elaborar a regulamentação 
dos direitos que estão apenas de forma abstrata previstos na Constituição.

O elemento de coordenação aborda a necessidade de articulação da participação entre os atores envolvidos no programa de ação governamental. Primeiramente deve-se entender a divisão de competências entre os Poderes, como o Legislativo que irá elaborar os marcos normativos e fica responsável por aprovar o projeto de lei orçamentária que por sua vez será elaborado pelo poder Executivo.

Ainda há a necessidade de articular as competências e divisão de responsabilidades entre as esferas da Federação, justamente por muitas vezes essa divisão não se mostrar de forma muito clara e isso dificultar a execução do programa nos diversos âmbitos (federal, estadual e municipal) devido à falta de uma organização do que cabe a cada um, de forma específica.

Por último, considerando a complexidade dos problemas sociais e da necessidade de se considerar diversos aspectos em um só direito social, é muito importante articular diversos órgãos do governo para tornar a efetivação do programa multidisciplinar, levando em consideração as mais variadas áreas constantes de um mesmo programa, devendo articular diferentes Secretarias, Ministérios.

Passando para o elemento do processo deve-se levar em consideração que os direitos sociais não pretendem ser implementados todos de uma vez, mas sim, devem fazer parte de processos progressivos de implementação. Processos esses, para além do direito, de natureza administrativa, orçamentária, até mesmo processos de participação popular, que requerem o estabelecimento de metas em um determinado período para que se possa realizar estudos objetivando a efetividade dos processos de implementação dos direitos sociais.

Por fim, o último elemento, consistente no programa que representa o conteúdo da política pública que por sua vez representa o resultado das opções políticas, definido dessa maneira quais as características da ação governamental como suas prioridades, os destinatários, duração, os meios.

Para entender como esses elementos se relacionam importante entender os processos que envolvem desde a elaboração até a verificação da efetividade e uma política 
pública. Ainda com as contribuições de Clarice de Seixas Duarte (2013), passaremos a organizar minimamente, de forma mais geral, o ciclo da politicas públicas para que se possa entender de forma mais estrutural.

As fases do ciclo abrangem a formulação, a execução, a avaliação e a fiscalização e controle. A formulação nada mais é do que a realização de estudos prévios para entender quais são as áreas de mais vulnerabilidade, entender quais os recursos disponíveis para a execução de um programa, justamente para que se tenha uma base possível de ser usada como ponto de partida para estabelecer aspectos como tempo de duração da política, recursos necessários, o público-alvo.

Importante destacar que quem tem iniciativa desse processo é o Poder Executivo na definição da política pública e o Poder Legislativo com a edição de normas que vão estabelecer as condições de fruição concreta dos direitos, sendo o Poder Judiciário protagonista político apenas em caso de omissão dos demais ${ }^{4}$, devendo-se ter cautela em relação ao movimento de judicialização das políticas públicas.

Já a fase de execução basicamente se presta para a efetivação dos aspectos estudados e elaborados na fase de formulação e que, dependendo da forma que é executado o programa podendo gerar responsabilização do Estado caso fique comprovada má organização, efetivação de gastos etc.

A fase de avaliação se refere ao momento de verificar se as metas estipuladas foram atingidas, de maneira geral a efetividade da política pública. O que geralmente é feito é a elaboração de pesquisas e relatórios pelos órgãos que participaram das fases de formulação e execução, o que torna a avaliação incompleta, necessitando de estudos de atores que não participaram no início do processo.

Por fim, a fase de fiscalização e monitoramento é realizada tanto pela sociedade civil como também pelos Tribunais de Contas e o Ministério Público. Sobre a discussão sobre um possível controle judicial da efetivação de direitos sociais, não sendo possível um debate mais aprofundado, nos limitaremos a nos posicionar conforme o seguinte

A promoção do diálogo entre os Poderes Públicos com o objetivo de contribuir para a realização de direitos constitui uma tarefa importantíssima a ser desempenhada pelo Judiciário no quadro de um Estado Social,

\footnotetext{
${ }^{4}$ Agravo Regimental no Recurso Extraordinário no 410.715-5.
} 
de modo a permitir a verificação da presença e adequação dos elementos necessários para a configuração de uma política pública. (DUARTE, 2013, p. 23)

Passando pelos elementos estruturais e como eles se relacionam dentro do ciclo das políticas públicas possível passar para a análise de como a Política Nacional para implementação da Justiça Restaurativa foi elaborada e está sendo efetivada, a partir de uma base mínima estrutural agora estabelecida.

\section{Processo de implementação das práticas restaurativas no estado de São Paulo a partir da Resolução no 225 do CNJ}

Após o estabelecimento das formas estruturais de uma política pública e de colocar os primeiros projetos de Justiça Restaurativa passemos a analisar o processo de desenvolvimento do marco normativo e seus desdobramentos.

Anterior ao marco normativo importante destacarmos o contexto com o Provimento CG N³5/2014 que dispõe sobre a implementação da Justiça Restaurativa no âmbito das Varas da Infância e da Juventude do Estado de São Paulo levando em consideração as possibilidades criadas pela Lei do SINASE ${ }^{5}$ e do Estatuto da Criança e do Adolescente $^{6}$.

Outro contexto é a Portaria № 16 de 26 de fevereiro de 2015, que dispõe sobre as diretrizes de gestão da Presidência do Conselho Nacional de Justiça para o biênio 2015-2016 que trazia o papel do CNJ na implementação da Justiça Restaurativa:

Art. 1ํ Ficam instituídas as diretrizes de gestão da Presidência do Conselho Nacional de Justiça para o biênio 2015-2016: (...) VII - contribuir com o desenvolvimento da Justiça Restaurativa; (CNJ, 2015).

Assim sendo, posteriormente com a Portaria 74, de 12 de agosto de 2015 do CNJ, ficou instituído o Grupo de Trabalho formado por juízes, desembargadores e integrantes do próprio CNJ para contribuir com o desenvolvimento da Justiça Restaurativa.

\footnotetext{
${ }^{5}$ Lei $n^{\circ}$ 12.594/2012, em seu art. 35, inc. II da estabelece o princípio da excepcionalidade da intervenção judicial e da imposição de medidas, apontando para o favorecimento de meios de autocomposição de conflitos e no inc. III, estabelece o princípio da prioridade de práticas ou medidas que sejam restaurativas e que, sempre que possível, atendam às vítimas;

${ }^{6}$ Lei 8.069/90 em seu art. 40, em consonância com o art. 227 da Constituição Federal, estabelece que as respostas a situações de vulnerabilidade, e infracionais, deverão se fazer dentro de uma lógica de fluxo interinstitucional e sistêmica, em articulação com a Rede de Garantia de Direitos; Justiça Restaurativa, para evitar disparidades de orientação e ações, e para assegurar a boa execução da política pública respectiva, respeitadas as especificidades de cada segmento da Justiça;
} 
Deste Grupo de Trabalho que foi elaborado o marco normativo, a Resolução no225 de 31 de maio de 2016 do Conselho Nacional de Justiça, que dispõe sobre a implementação da Política Nacional de Justiça Restaurativa no âmbito do Poder Judiciário, estabelecendo a utilização das práticas restaurativas e trazendo em seu artigo $1^{\circ}$ a definição:

\begin{abstract}
Art. 1ำ A Justiça Restaurativa constitui-se como um conjunto ordenado e sistêmico de princípios, métodos, técnicas e atividades próprias, que visa à conscientização sobre os fatores relacionais, institucionais e sociais motivadores de conflitos e violência, e por meio do qual os conflitos que geram dano, concreto ou abstrato, são solucionados de modo estruturado na seguinte forma: (CNJ, BRASIL, 2016).
\end{abstract}

A Resolução no 225/2016 foi muito pautada em Resoluções da ONU como por exemplo a no 2002/12 intitulada como "Princípios básicos para a aplicação de programas de justiça restaurativa em matéria criminal" que traz o enunciado

20. Os Estados Membros devem considerar a possibilidade de formulação de estratégias e políticas nacionais objetivando o desenvolvimento da justiça restaurativa e a promoção de uma cultura propícia a sua utilização entre as autoridades policiais, judiciais e sociais, bem como entre as comunidades locais." (ONU, 2012).

Resolução no 225/16 foram estabelecidas as competências do CNJ e dos Tribunais de Justiça como os responsáveis pela implementação, articulação, monitoria e avaliação dos programas e projetos.

Ao CNJ ficaram estabelecidos linhas programáticas para a organização do programa, quais sejam: caráter universal (proporcionando acesso a procedimentos restaurativos no Poder Judiciário) caráter sistêmico (buscando nos casos a integração das redes familiares e comunitárias, assim como das políticas públicas relacionadas), caráter interinstitucional (proporcionar a participação das diversas instituições bem como das organizações da sociedade civil), caráter interdisciplinar (propiciar o tratamento do conflito a partir de diversas áreas do conhecimento), caráter intersetorial (buscando articulação com outras políticas públicas), caráter formativo (formação de facilitadores) e caráter de suporte (avaliação).

A Resolução № 225/16 conferiu à Presidência do CNJ, com o apoio da Comissão Permanente de Acesso à Justiça e Cidadania, a atribuição de instituir e regulamentar o Comitê Gestor da Justiça Restaurativa que o fez através da Portaria № 91 de 17 de agosto de 2016 que entendeu por ter a composição de conselheiros e um juiz auxiliar da 
presidência do CNJ e 4 magistrados.

Conforme estabelecido no artigo $5^{\circ}$ da Resolução $n^{\circ}$ 225, foi atribuído aos Tribunais a competência de criar um órgão responsável pela a organização e implementação dos programas. Assim sendo, através do Provimento do Conselho Superior da Magistratura no 2416 de 2017, ficou instituído o Grupo Gestor da Justiça Restaurativa no âmbito da Coordenadoria da Infância e da Juventude do Tribunal de Justiça do Estado de São Paulo.

Este Grupo Gestor foi designado para ter em sua composição desembargadores da própria Coordenadoria e magistrados que tenham experiencia na área de Justiça Restaurativa. Importante salientar a possibilidade da participação de servidores integrantes das Equipes Técnicas e de Apoio Administrativo da Coordenadoria da Infância e da Juventude, que atuem na esfera da Justiça Restaurativa.

No caso do estado de São Paulo foi criado o método de "polo irradiador" para implementar os programas de Justiça Restaurativa que pretende articular outros atores sociais para além do poder judiciário trabalhando os aspectos relacionais, institucionais e estruturais que essa metodologia se propõe.

Conforme afirma Egberto Penido ${ }^{7}$

Os "polos irradiadores" são locais (necessariamente com a participação direta ou com o acompanhamento do Judiciário local) que recebem a proposta, inovando a prática de resolução de conflito, que visa, em última instância, à harmonização justa dos conflitos nas três dimensõesrelacional, institucional e social -, por meio da implementação da Justiça Restaurativa. Na medida em que a instituição é identificada e passa a integrar a proposta de adesão (após preencher critérios mínimos para a participação), a ClJ oferece o suporte necessário para dar início à implementação. Como método de trabalho, pautado na lógica da Justiça Restaurativa, o grupo desenvolve planos de ação que estabelecem os passos a serem estruturados na região. (MUMME, PENIDO, 2014, p. 80).

Cada "polo irradiador" tem o propósito de incluir e desenvolver a mudança do paradigma tanto externamente convidando instituições parceiras para articular o trabalho em Rede e internamente com a realização de formação considerando os três eixos estruturantes para a Justiça Restaurativa.

\footnotetext{
${ }^{7}$ Juiz titular da $1^{\text {a }}$ Vara Especial da Infância e da Juventude de São Paulo. Juiz membro da Coordenadoria da Infância e Juventude (CIJ). Coordenador da Seção de Justiça Restaurativa da CIJ e do Centro de Estudos de Justiça Restaurativa da Escola Paulista de Magistratura (EPM).
} 
Este é um panorama geral do processo de implementação no Estado de São Paulo e quais os mecanismos utilizados, agora passemos ao objetivo do presente artigo, qual seja a análise dos obstáculos enfrentados nesse processo.

\section{Propósitos da Justiça Restaurativa e a dificuldade de institucionalização de suas práticas}

Primeiramente, após entender o fluxo da implementação da Justiça Restaurativa no Estado de São Paulo, particularmente na capital, podemos destacar algumas dificuldades enfrentadas justamente devido ao desenho jurídico-institucional da Política Nacional.

O primeiro ponto é que o contexto do surgimento da necessidade da elaboração de uma implementação era a demanda crescente por meios alternativos de resolução de conflitos, como por exemplo a institucionalização das práticas com a criação em 2011 dos Centros Judiciários de Solução de Conflitos e Cidadania (Cejuscs) no Tribunal de Justiça de São Paulo. Muito devido, como anteriormente mencionado, à crise da instituição do judiciário que não mais consegue absorver os conflitos inerentes a estrutura social.

Sendo assim, importa dizer que o fato do Conselho Nacional de Justiça e os Tribunais, ou seja, o judiciário, estar protagonizando a iniciativa e toda a articulação da implementação faz com que haja limitação das possibilidades considerando que o próprio judiciário é que se encontra em crise de legitimidade e de capacidade de absorção dos conflitos e ainda assim é o responsável pela elaboração de uma Política Nacional que se restringe ao seu âmbito.

O que acaba por reduzir até mesmo o alcance das potencialidades da Justiça Restaurativa levando em conta o fato de que a Politica Nacional poderia estar articulada para a implementação em outros âmbitos para além do judiciário.

Como bem afirma Egberto Penido (2016) a ideia ao se questionar o protagonismo do poder judiciário na implementação das práticas restaurativas não se presta de forma alguma a destituir a legitimidade do Poder Judiciário na construção e consolidação do estado democrático de direito. 
que significa efetivamente lidar com a complexidade das violências, suas causas e variáveis, e quais estruturas precisam ser revistas para a desconstrução da lógica violenta, que até então utilizou se de ações reducionistas de punição e exclusão (PENIDO, 2016, p. 207).

Considerando essa problemática, o poder judiciário no estado de São Paulo elaborou a implementação da Justiça Restaurativa em três principais eixos: o relacional, o institucional e o estrutural. Sobre a questão da lógica da instituição Monica Mumme e Egberto Penido trazem os aspectos do segundo eixo de implementação.

Um segundo eixo tem seu foco na mudança institucional. Aqui também se cuida de uma formação - mas uma formação diferenciada - que tem seu foco na preparação das pessoas que dizem "sim" ao projeto, para que elas se tornem agentes de mudança institucional; ou seja, para que pessoas afetas à instituição onde as técnicas restaurativas se fazem possam cuidar da efetiva transformação da ambiência institucional, a fim de que a própria estrutura e cultura reinante (invariavelmente hierárquica e excludente) não retroalimente a situação de violência, bem como não manipule os procedimentos restaurativos para manter as relações de poder na instituição; e, ainda, para que a proposta não seja esvaziada e extinta. (MUMME, PENIDO, 2017, p.77)

Neste cenário que foi desenvolvida a metodologia dos "polos irradiadores" que como já colocado ficaram responsáveis por realizar as articulações necessárias com outras áreas para além do judiciário, reunindo a rede de apoio que abrange a saúde, educação, assistência social e etc. Deste modo evitando a continuidade de um processo hierarquizado sem a participação coletiva.

Outro aspecto importante quando olhamos para políticas públicas é a importância da institucionalização para evitar que a continuidade de um programa dependa de iniciativas pessoais de forma que crie instabilidade e há ausência de um processo progressivo de implementação. No caso das práticas restaurativas além desse aspecto da continuação dos programas, observa-se a institucionalização como forma de legitimação e de credibilidade do uso dessa metodologia.

Ocorre que, ainda que haja toda essa importância ligada a institucionalização, existem vários obstáculos para que isso aconteça com as práticas restaurativas justamente por elas representarem toda uma mudança de paradigma e de forma de se relacionar. Trata-se de uma clara oposição entre as duas lógicas: a restaurativa e a retributiva.

O questionamento é como implementar práticas restaurativas em uma instituição que opera em um processo antagonista. Nesse sentido é que aborda a necessidade de 
uma mudança na estrutura social, resgatando os valores humanizantes como já trazidos por João Salm (2017).

Trazendo também esse questionamento

More difficult than promoting our habits of the heart is revisioning and creating institutions that allow a culture of those habits to exist. We must ask, "If we are to create a culture of restorative justice, and the habits of living a life of value and relationships, do the orientations of our institutions need to be changed?" "Do our institutions need to function in a nonpunitive, caring, and relational way?" (HASS, KAYINGO, SALM, 2017, p. 367).

Essa problemática não afeta apenas de forma generalizada, mas em aspectos bem específicos como a terminologia usada nos processos judiciais, "réu" e "vítima", e que a Justiça Restaurativa busca não utilizar evitando a rotulação das pessoas e a perda de suas complexidades por um olhar reducionista.

Outro ponto é a avaliação do programa que parte de critérios objetivos para verificar a efetividade de suas ações como por exemplo mapear a quantidade de acordos realizados como maneira de entender se a metodologia está funcionando. Ocorre que para a Justiça Restaurativa, como já colocado, um dos princípios aborda as relações como centrais nos conflitos, então ainda que não haja acordo formal pode-se considerar uma prática exitosa se para os participantes aquelas relações foram tratadas e ressignificadas.

Um ótimo exemplo da dificuldade de integrar as práticas restaurativas dentro de uma instituição que muito difere do modo de funcionamento da Justiça Restaurativa é o artigo 562 do Projeto de Lei 7.006/06

Art. 562 -O acordo restaurativo deverá necessariamente servir de base para a decisão judicial final. Parágrafo Único - Poderá o Juiz deixar de homologar acordo restaurativo firmado sem a observância dos princípios da razoabilidade e da proporcionalidade ou que deixe de atender às necessidades individuais ou coletivas dos envolvidos. (BRASIL, PL 7006, 2006).

Claramente, o fato de devolver ao juiz a possibilidade de não homologar acordo que foi construído pelas partes, de acordo com as necessidades individuais e coletivas, por motivo do magistrado, por seus entendimentos, achar que não está atendendo às necessidades dos envolvidos, faz com que volte ao modelo de terceirização do conflito ${ }^{8}$

\footnotetext{
${ }^{8}$ Expressão utilizada para se referir ao movimento dos processos judiciais no qual as pessoas mais
} 
, deixando novamente os atores principais e mais interessados no conflito de lado e sem autonomia.

Não se pretendendo esgotar, mas trazendo mais um ponto que se mostra de difícil arranjo é o fato da Justiça Restaurativa ter como princípio o fortalecimento da comunidade, portanto, ser protagonista e o locus do desenvolvimento das práticas restaurativas. Como a lógica tradicional ainda entende a responsabilização apenas como um processo individual e como o movimento da Política Nacional iniciou-se de forma hierárquica pouco se possibilitou da participação da comunidade nesses processos de implementação. que perde novamente muito do seu potencial, já que se considera que não adianta mudar um indivíduo, mas deve-se pensar em uma mudança de relações, de modos de se relacionar para que assim as mudanças sejam efetivas e façam parte daquela comunidade.

A comunidade é o locus para difusão dos valores morais compartilhados e é exatamente por esse motivo que tantos autores que falam sobre Justiça Restaurativa, considerando-a como um convite à uma mudança estrutural da maneira de se relacionar, enfatizam a importância de devolver a comunidade o protagonismo em resolver seus conflitos e se apropriar do processo de implementação das práticas restaurativas. Nesse sentido

\begin{abstract}
Aponta-se como importante elemento neste adensamento teórico, a fim de possibilitar uma maior capacidade de compreensão da justiça restaurativa, que ela não se resume à resolução de conflitos, sendo também práticas que se propõem a reconstruir a vida em comunidade, sendo uma ética comunitária e emancipatória. E desta feita, não se resume às dinâmicas direcionadas a este ou àquele caso, ou ainda, não àquela resposta tópica, visto que se insere em sociedades complexas e comunidades permeadas de indivíduos e suas realidades contextualizadas que não permitem/buscam definições isoladas, descontextualizadas e alienígenas sob pena de não dar conta (tal qual a juridicidade ordinária) das necessidades de respostas que os indivíduos precisam para suas relações e conflitos. (LEAL, SALM, 2012, p. 207)
\end{abstract}

\title{
Corroborando para esse sentido temos também que
}

A Justiça Restaurativa, portanto, não se limita a uma técnica de resolução de conflitos, mas a um feixe de ações coordenadas (um programa) que prevê metodologias de resolução e transformação de conflitos; bem como, concomitantemente, prevê ações que levem à mudança da instituição onde tais práticas são desenvolvidas; e, ainda, prevê a articulação

interessadas na administração daquele conflito "terceirizam" a sua solução para pessoas estranhas ao conflito que jamais vão conseguir ter a profundidade de entendimento e vivência sobre qual seria o melhor caminho. 
de "redes locais" em torno dessas ações. (MUMME, PENIDO, 2014, p. 76-77).

Tendo em vista esse contexto podemos entender os obstáculos enfrentados para a implementação das práticas restaurativas considerando que a mudança de paradigma necessariamente precisa partir da comunidade e por ela protagonizada.

Para além disso, o fato da Justiça Restaurativa partir da premissa de que justiça é um valor compartilhado e a instituição do judiciário partir da premissa que a justiça é a materialização da aplicação de uma sanção, faz com que quando há a incorporação das práticas restaurativas por uma instituição nessas características muito se perde e deturpa de suas potencialidades. Como afirma George Pavlich (2009) dizendo que os perigos da incorporação podem ameaçar a aspiração fundadora de oferecer novas visões de justiça.

O que muito difere do modelo tradicional de justiça que se preocupa apenas com o aspecto jurídico e formal da norma, criando uma distância entre os principais atores e, portanto, principais interessados em resolver o conflito de maneira a não criar um ambiente propicio para tratar aspectos emocionais e relacionais.

\begin{abstract}
O fato é que, no âmbito de um Estado Social e Democrático de Direito, o que se exige, como já destacado, é a atuação coordenada dos Poderes Públicos em prol da efetivação de direitos, destacando-se, ainda, a atuação da sociedade civil, que deve assumir uma postura ativa não apenas no processo de elaboração das políticas públicas - por meio da sua presença em conselhos de direitos, audiências públicas, além das iniciativas referentes ao chamado "orçamento participativo" -, como também nas instâncias de fiscalização e controle, o que pode ocorrer, justamente, por meio da propositura de ações judiciais (DUARTE, 2013).
\end{abstract}

Podendo entender que a Justiça Restaurativa encontra dificuldades de institucionalização considerando que a Política de implementação teve origem no CNJ e conta com um Grupo Gestor formado majoritariamente por juízes e desembargadores, tornando difícil e delicada sua aplicação apenas como uma prática, requisitando uma análise mais profunda nas estruturas para além de uma prática a ser implementada e os cuidados que isso exige.

\title{
Considerações finais
}

Finalizadas as reflexões acerca do tema de políticas públicas e sobre o processo de implementação da Justiça Restaurativa no Brasil, inclusive de sua Política Nacional, 
podemos entender que pelo judiciário ser definido para ser o locus dos conflitos fez com que facilmente tenha se tornado o protagonista neste processo, não devendo ser negada e nem ignorada sua importância, mas sim estar em constante avaliação para que os princípios e os valores da Justiça Restaurativa não sejam deturpados, percam os seus potenciais e que mecanismos sejam criados para que a implementação respeite esses dois aspectos

Ainda que existam diversas dificuldades em sua Política e em sua implementação, como se trata de um assunto e de práticas muito recentes o processo deve mesmo ser cauteloso e sem pressa para que a medida que as ações sejam planejadas e executadas surjam as possibilidades de modificar formatos que não correspondam com os propósitos da Justiça Restaurativa.

Sendo assim, considerando o contexto de crise do poder judiciário e da legitimidade como um todo, e principalmente por estar acontecendo o processo de implementação das práticas restaurativas na instituição, é de suma importância que o debate sobre o tema continue acontecendo com o objetivo de atentar sobre todos os aspetos - relacional, institucional e estrutural - desse processo, com a consciência de que a Justiça Restaurativa não é e não deve ser considerada nesse processo como apenas práticas alternativas a serem institucionalizadas.

\section{Referências}

ARRUDA, Eloisa de Sousa; JOÃO, Camila Ungar. A Justiça Restaurativa e sua Implantação no Brasil. Escola Superior da Defensoria Pública da União: Brasília, DF n. 7 p. 187-210, 2014.

ASSEMBLÉIA GERAL DA ONU. Resolução n. 2002/12. Princípios básicos para a aplicação de programas de justiça restaurativa em matéria criminal. Onu: 2002.

BRASIL. Portaria n. 74, de 12 de agosto de 2015. Institui Grupo de Trabalho para contribuir com o desenvolvimento da Justiça restaurativa. CNJ, Brasília DF: ago 2015.

BRASIL. Projeto de Lei 7006, de 10 de mai. de 2006. Facultar o uso de procedimentos de Justiça Restaurativa no sistema de justiça criminal, em casos de crimes e contravenções penais. Brasília, DF, mai 2006.

BRASIL. Provimento CSM n. 2416, de 25 de abr. de 2017 - Institui o Grupo Gestor da Justiça Restaurativa no âmbito da Coordenadoria da Infância e da Juventude do Tribunal de Justiça do Estado de São Paulo. Brasília, DF, abr. 2017

BRASIL. Resolução n. 225, de 31 de mai. de 2016. Institui Política Nacional de Justiça 
Restaurativa no âmbito do Poder Judiciário,CNJ, Brasília,DF: mai 2017.

BUCCI, Maria Paula. O conceito de políticas públicas em direito. In: BUCCI, Maria Paula Dallari (org.). Políticas Públicas: reflexões sobre o conceito jurídico. São Paulo: Editora Saraiva, 2006, p. 1-49.

DUARTE, Clarice Seixas. O Ciclo das Políticas Públicas. In SMANIO, Gianpaolo Poggio; BERTOLIN, Patrícia Tuma Martins e BRASIL, Patricia Cristina (orgs.). O Direito e as Políticas Públicas no Brasil. São Paulo, Atlas, 2013, pp.16-43.

HASS, Virginia McCoy; KAYINGO, Gerald; SALM, João. Creating a Culture of Restorative Justice. In: The Health Professions Educator: A Practical Guide for New and Established Faculty, Spring Publisher: 2017, p. 359-368.

LEAL, Jakson da Silva; SALM, João. A Justiça Restaurativa: multidimensionalidade humana e seu convidado de honra. Sequência, n. 64, p.195 226. Cidade: editora, 2012.

MORRISON, Brenda. Justiça Restaurativa nas Escolas. In: Justiça Restaurativa. Brasília: Ministério da Justiça/ Programa das Nações Unidas para o Desenvolvimento (PNUD), 2005, p. 295-319.

MUMME, Monica Maria Ribeiro; PENIDO, Egberto de Almeida. Justiça Restaurativa e suas Dimensões Empoderadoras. Revista do Advogado, Ano XXXIV, n. 123. São Paulo, 2014.

ORSINI, Adriana Goulart de Sena; LARA, Caio Augusto Souza. Dez anos de práticas restaurativas no Brasil: a afirmação da justiça restaurativa como política pública de resolução de conflitos e acesso à Justiça. Revista Responsabilidades (TJMG), Belo Horizonte, v. 2, n. 2, p. 305-324, set. 2012/fev. 2013.

PAVLICH, George. Justice Fragmented: Mediating Community Disputes Under Postmodern Conditions, London: Routledge, 1996. _ Critical policy analysis, power and restorative justice. In: Criminal Justice Matters, v.75, n. 1. Routledge: 2009, p. 24-25.

PENIDO, Egberto de Almeida, et. al. Justiça Restaurativa e sua humanidade profunda: diálogos com a Resolução 225/2016 do CNJ. Justiça Restaurativa: Horizontes a partir da

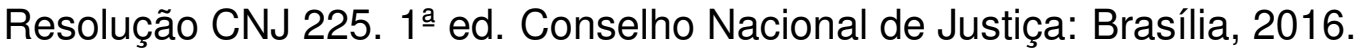

RAUPP, Mariana; BENEDETTI, Juliana Cardoso. A implementação da Justiça Restaurativa no Brasil: Uma Avaliação dos Programas de Justiça Restaurativa de São Caetano do Sul, Brasília e Porto Alegre. Revista Ultima Ratio. Rio de Janeiro: Lumen Juris, 2007, p. 13.

SMANIO, Gianpaolo Poggio Legitimidade jurídica das políticas públicas: a efetivação da cidadania. In: SMANIO, Gianpaolo Poggio; BERTOLIN, Patrícia Tuma Martins (Orgs.). O Direito e as Políticas Públicas no Brasil. São Paulo: Editora Atlas, 2013, p. 3-15.

ZEHR, H. Changing Lenses: a new focus for crime and justice. Waterloo, Canada: Herald Press, 1990. 